\title{
Conflict Processing and Response Inhibition in Patients with Temporal Lobe Epilepsy: fMRI Study
}

\author{
Alvarez-Alamilla $\mathrm{J}^{1}$, Velasco $\mathrm{AL}^{2^{*}}$ and Río-Portilla $\mathrm{YD}^{1}$ \\ ${ }^{1}$ Psychology School, Universidad Nacional Autónoma de México, Mexico \\ ${ }^{2}$ Epilepsy Clinic, Hospital General de México "Dr. Eduardo Liceaga”, Mexico City, Mexico \\ “Corresponding author: Dr. Ana Luisa Velasco, Epilepsy Clinic, Hospital General de México “Dr. Eduardo Liceaga”, Mexico City, Mexico, Tel: 0445554097631; E-mail: \\ analuisav@yahoo.com
}

Received date: Aug 12, 2016; Accepted date: Aug 30, 2016; Published date: Sep 02, 2016

Copyright: @ 2016 Alvarez-Alamilla J. This is an open-access article distributed under the terms of the Creative Commons Attribution License, which permits unrestricted use, distribution, and reproduction in any medium, provided the original author and source are credited.

\begin{abstract}
We evaluate the conflict processing and response of inhibition with the Stroop task in patients with intractable temporal lobe epilepsy who underwent depth electrode amygdala-hippocampal recording to determine focus laterality for further lobectomy and control subjects analyzing the cerebral metabolic response by fMRI. Patients showed longer reaction times and more errors in the Stroop task than control subjects. At the conflict processing and response of inhibition, TLE patients presented difficulties in the executive system regulated by the frontal lobe; they showed dominant brain activation in the right hemisphere frontal lobe and right inferior frontal junction, inferior frontal, superior frontal, middle frontal gyri and ACC. Patients did not show left activation, as observed in control subjects.
\end{abstract}

Keywords: Temporal lobe epilepsy; fMRI; Stroop; Executive functions; Anterior cingulate; Frontal lobe

\section{Introduction}

Temporal Lobe Epilepsy (TLE) was defined in 1989 by the ILAE [1] as a syndrome characterized by recurrent, unprovoked crises that originate in the medial or lateral portion of the temporal lobe. This is the most frequent type of focal epilepsy, and it is considered a medical and social problem, since $30 \%$ of such patients are drug-resistant to treatment [2,3]. Therefore, epilepsy has been considered a public health problem, for there are approximately 50 million patients whose quality of life has been affected; OMS [4] studies have demonstrated that epilepsy can cause alterations in the cerebral functioning of patients [5] who have a high risk of presenting cognitive deterioration and behavioral abnormalities [6,7] that can compromise their personal, academic, work and social development [8-11].

Studies conducted on the neurocognitive effects in TLE patients suggest that individuals who report early onset and greater duration of this disease are at higher risk of developing cognitive dysfunction [12-14]. About $70 \%$ of patients with TLE present problems with memory associated with the pathological state of the hippocampus and adjacent structures [15-17]. The pathological condition of the hippocampus in TLE patients has also been associated with alterations of the executive functions $(\mathrm{EF})[18,19])$ that are regulated by the frontal lobe (LF) according to Martín González et al. [20]. Several hypotheses have been proposed to explain these alterations; for example, that the $\mathrm{EF}$ have an underlying dysfunction in the frontotemporal connections [21], or that the hippocampus can intervene in some areas of the EF [22] by forming a cognitive network assigned to process them [23].

Recent research has found extra-temporal abnormalities in the gray and white matter of the Frontal Cortex (CF) in association with the mediation of some functions of the executive system [24-27]. Other hypotheses have been derived from the proximity of the temporal lobe to the FC according to Jack et al. [28], the pathological condition of the hippocampus, and the propagation of epileptic activity that affects the extra-temporal regions which regulate the frontal executive system [29-32]. Alterations in the temporofrontal, frontostriatal and orbitomedial circuits have shown a dysexecutive pattern related to failures in the hippocampus in its role as comparer of action, for example, information previously stored in memory cannot be evoked to guide future actions $[22,33]$.

Some studies assessing executive function tasks, regulated by the frontal cortex, have demonstrated that patients with temporal lobe epilepsy present lower performance et al., $[25,34,35]$ according to our clinical experience obtained through different neuropsychological tests (Epilepsy Surgery Clinic of General Hospital of Mexico "Dr. Eduardo Liceaga") [36]; however, the results have not been convincing [37-39]. There is no agreement if the possible effects of the behavioral or physiological assessment could be affected due to the temporal lobe epilepsy; therefore, our objective was to analyze the brain's metabolic response using the fMRI BOLD technique and the Stroop task to obtain conflict processing and response of inhibition which are cognitive skills regulated by the Frontal Cortex (FC) in patients with TLE.

Several studies using this neuroimaging technique with normal subjects have shown that there is a strong relation within the areas of the bilateral Anterior Cingular Cortex (ACC) BA 32, Inferior Parietal Lobe (IPL) right BA [40], Medial Frontal Gyrus (MFG) left BA [41] and the insula cortex (BA, Brodmann area) $[40,42]$.

Our findings may reveal if patients with TLE present difficulties related to conflict processing and response of inhibition, also if the brain's metabolic response differs from the one observed in normal subjects $[41,43,44]$. In the present study, we used not only a behavioral task but a physiological measure as fMRI as well, in order to provide 
more information and to demonstrate if there is a cerebral reorganization caused by the damage due to TLE.

\section{Data and Methods}

The study was approved by The Ethical and Research Committees of the General Hospital of Mexico, "Dr. Eduardo Liceaga". Patients and family signed an informed consent. The study involved 12 patients at the Epilepsy Clinic of the General Hospital of Mexico "Dr. Eduardo Liceaga" with diagnoses of TLE resistant to pharmacologic treatment, surgery candidates (Table 1) and 12 control participants paired by age and scholarship, to have a systematic control of the execution in the
Stroop task in order to obtain differences between groups in reaction times and in behavioral responses. Epileptic patients were surgical candidates and as such, they underwent Phase I (noninvasive) and Phase II (invasive) studies. Phase I included neurophsychology batteries including Stroop test, EEGs, MRI, study protocol with fMRI. Phase II included depth electrode recording with 8 contact amygdalohippocampal electrodes implanted through occipital burr holes. Continuous video-EEG monitoring of interictal and ictal activities were performed till the epileptic focus location and laterality was determined. The focus laterality was confirmed with 1 year postoperatory follow up and used for the present study.

\begin{tabular}{|l|l|l|l|l|l|l|l|l|l|}
\hline $\begin{array}{l}\text { Patients } \\
\mathbf{N}\end{array}$ & $\begin{array}{l}\text { Age } \\
\text { (years) }\end{array}$ & Gender & $\begin{array}{l}\text { Educatio } \\
\mathbf{n} \\
\text { (years) }\end{array}$ & $\begin{array}{l}\text { Age } \\
\text { onset } \\
\text { (years) }\end{array}$ & $\begin{array}{l}\text { of } \\
\text { 年ilepsy } \\
\text { (years) }\end{array}$ & $\begin{array}{l}\text { of } \\
\text { frecuency } \\
\text { (per month) }\end{array}$ & $\begin{array}{l}\text { Type } \\
\text { seizures }\end{array}$ & Therapy \\
\hline 1 & 38 & M & 18 & 10 & 27 & 20 & CPS & CBZ, VPA \\
\hline 2 & 49 & M & 6 & 15 & 34 & 30 & CPC-SGS & VPA-CBZ & TLE-R \\
\hline 3 & 30 & F & 12 & 6 & 24 & 10 & CPC-SGS & LTG-CBZ \\
\hline 4 & 44 & F & 11 & 21 & 23 & 17 & CPC-SGS & AVP-OXC & TLE-R \\
\hline 5 & 24 & M & 11 & 14 & 10 & 3 & CPS-SGS & OXC & TLE-R \\
\hline 6 & 24 & M & 18 & 0 & 24 & 30 & CPC & CBZ,PHT,LTG & TLE-L \\
\hline 7 & 26 & F & 6 & 6 & 20 & 90 & CPC-SGS & CBZ,VPA,CZB,LTG & TLE-L \\
\hline 8 & 37 & F & 5 & 4 & 33 & 60 & CPC-SGS & OXC-VPA & TLE-L \\
\hline 9 & 39 & F & 16 & 6 & 23 & 2 & CPC & VPA-PHT-OXC- PRIM & TLE-L \\
\hline 10 & 25 & M & 12 & 14 & 11 & 10 & CPC-SGS & VPA,OXC \\
\hline 11 & 34 & M & 16 & 17 & 17 & 6 & CPC & VPA,PNT,OXC,TOP & TLE-B \\
\hline 12 & 24 & F & 12 & 12 & 12 & 4 & CPC-SGS & VPA,CBZ, OXC & TLE-B \\
\hline $\mathrm{X} \pm \mathrm{SD}$ & $32.4 \pm 8.6$ & $6 \mathrm{M} / 6 \mathrm{~F}$ & $11.9 \pm 4.5$ & $10.4 \pm 6.1$ & $21.5 \pm 7.9$ & $23.5 \pm 26.7$ & & & TLE-B \\
\hline
\end{tabular}

Table 1: Demographic and clinical data of the patients with temporal lobe epilepsy. Temporal Lobe Epilepsy TLE, Right R, left L, Bilateral, B. CPS, Complex partial seizures, SGS, Secondarily generalized seizures. LTG, Lamotrigine; CBZ, Carbamazepine; TOP, Topiramate; LVT, Levetiracetam; PNT, Phenytoin; PRIM, Primidone; VPA, Valproate, OXC, Oxcarbazepine. X, Average SD, Standard Deviation.

\section{Cognitive task}

To conduct this fMRI study, patients were first trained before entering the resonator. The training task was programmed and presented on a portable computer with a mouse provided to respond. The task was similar to the one that would be presented in the experimental process, but feedback was offered during training; i.e., once the patient responded to the item on the screen an indication of the quality of the answer appeared: 'Correct', 'Incorrect', or 'No response detected' (when a patient failed to respond in the time allotted). The purpose of this training was to ensure that the patients were able to understand the instructions, and to detect any problems in identifying the colors.

An adaptation of the Stroop Word Color task or "Stroop Effect" was used [45-47] (Figure 1) with a block design that included a control condition to compare with the results of the experimental condition of the process. Stimuli were generated by the E-Prime software [48]. The design consisted in presenting 4 conditions (read, color, motor, Stroop) in 25-s blocks. Each condition contained 360 stimuli shown randomly in two 8-minute sessions, including the instructions given between conditions. The stimuli were shown for $1350 \mathrm{~ms}$, separated by an interstimulus interval of $350 \mathrm{~ms}$. All stimuli were projected on a screen located at a distance of 3 millimeters from the patients, who viewed it through and responded using a button pad.

\section{Control and experimental conditions}

Control condition (read): The words 'red', 'green', 'yellow' and 'blue' were written in white and shown against a black background. Patients were instructed to focus their attention on the screen in order to read the words. When the stimulus appeared, they had to respond by pressing a button: If the word read was 'red' or 'yellow' they had to press button 1 (right), and button 2 (left) if the word was 'blue' or 'green'.

Control condition (color): This condition consisted in the presentation of a string of letters ' $\mathrm{x}$ ' $(\mathrm{xxxx})$ written in different colors 
('red', 'green', 'yellow' and 'blue'). Patients were told to identify the color of the ' $x$ ' by pressing one of the two buttons. If the stimulus was identified as 'red' or 'yellow', they had to press button 1, and press button 2 if the color was identified as 'blue' or 'green'.

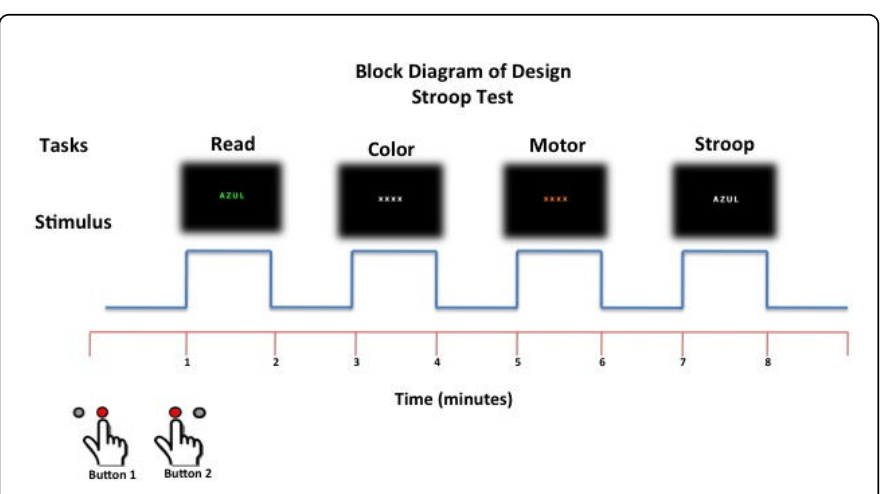

Figure 1: Schematic representation of experimental task and block design used for the Stroop task: Design configuration show the time in minutes (8 minutes), in the three control conditions: (motor, color, read) and the experimental condition (Stroop).

Control condition (motor): In this condition a string of letters ' $x$ ' (xxxx) was presented written in white on a black background. In this trial, patients had to respond by pressing alternately button 1 and button 2 .

Experimental condition (Stroop): This condition consisted in the random presentation of words written in colors ('red', 'green', 'yellow' or 'blue') but the color shown was different from the word written or the color read; i.e., "incongruent stimuli". The words always appeared in a random color that was necessarily different from that of the designated word (eg. the word 'blue' was written in red, yellow or green). The response for this condition consisted in pressing button 1 if the words were in 'red' or 'yellow', and button 2 if they were in 'blue' or 'green'.

\section{fMRI acquisition}

Functional MRI data was acquired with a General Electric Signal of 1.5 Tesla (HDx) system. For each subject and each session, the functional images were obtained with an EPI gradient echo sequence, with the sequence pondered at $\mathrm{T} 2{ }^{*}$ sensitive to BOLD contrast (Blood Oxygen Level Dependent). A total of 5400 images were obtained in 160 volumes, with 30 cuts and a TR of $3 \mathrm{~s}$. The lowest slice included the basal region orbitofrontal cortex, mesencephalon, superior region of cerebellum (culmen) and visual cortex. The uppermost slice included the superior frontal gyrus, pre and postcentral gyri and superior parietal lobe.

\section{Behavioral data}

Data were analyzed with IBM $^{\bigotimes}$ SPSS Statistics software v.20, obtaining measures for central tendency, mean and standard deviation. A Student $t$ test for independent samples was used to analyze the differences in reaction times and types of response among the TLE and control groups.

\section{fMRI data}

Processing of the fMRI images was performed with the SPM2 computer program (Statistical Parametric Mapping, Wellcome Department of Cognitive Neurology, London, UK). After correcting for possible head movements during the study, the images were normalized to allow localization of the activation in a standard MNI space (Montreal Neurological Institute). After this spatial normalization, the intensity of the images was softened using a Gaussian isotropic nucleus of $\mathrm{FWHM}=3 \mathrm{~mm}$. At that point we were able to proceed with the appropriate statistical analyses using the statistical test (Student t-test) to demonstrate statistically significant signal differences among conditions (read, color, motor, Stroop), and then generate statistically significant maps. Results of these t-contrasts from each subject were entered before the random-effects analysis at the group level. The threshold of statistical significance was set at $\mathrm{p}<0.01$, corrected by multiple comparison and clusters (groupings of voxels) that exceeded this level and were described with respect to their highest value and spatial extension.

\section{Results}

\section{Behavioral results}

Reaction times: The comparison of reaction times obtained during the Stroop Word Color task performance between the control and TLE groups are shown in Figure 2. Significant differences between groups were observed. The control group answered the task with lower reaction times, compared to the TLE group, $t$ test $(p<0.046)$. The control group completed the task in less time with the patients group with TLE, for conditions control: Condition Color $\mathrm{p}<0.001$, Read $\mathrm{p}<0.016$ and Motor $\mathrm{p}<0.007$ respectively.

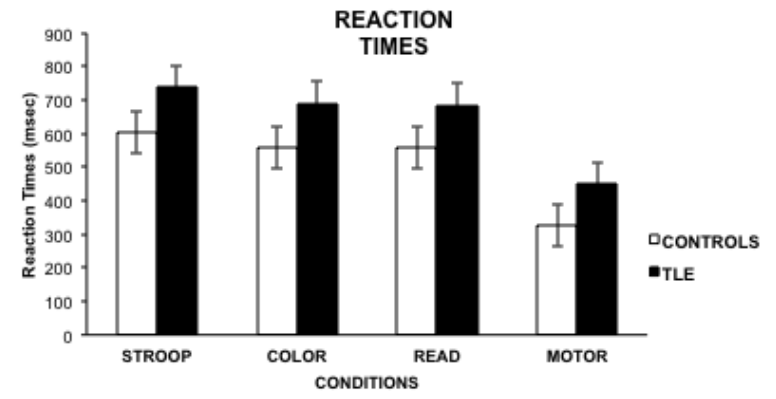

Figure 2: Graphic showing the significant effects obtained in the analysis of the behavioral data: mean and standard errors of the reaction times in $\mathrm{ms}$ for the control conditions (Color $(\mathrm{p}=0.001)$, Read $(\mathrm{p}=0.016)$ and Motor $(\mathrm{p}=0.007)$ and the Stroop task which is the experimental condition $(\mathrm{p}=0.046)$.

Accuracy: In order to analyze the behavioral answers we need to use the same type of test for the time of reaction analysis. The differences between the inhibition answers (Figure 3a) and the omissions or not answered items (Figure $3 \mathrm{~b}$ ) were contrasted with the controlled group and the group of patients with TLE. The findings showed that the group of patients with TLE significantly obtained the highest number of inhibition errors with a statistically difference of $(\mathrm{p}<0.048)$; 
furthermore, in the control conditions, some differences were found such as in the Color conditions $(\mathrm{p}<0.005)$ and in the Read conditions $(\mathrm{p}<0.03)$; but in the controlled Motor conditions $(\mathrm{p}=0.22)$ no difference was found. According to our results, comparing the control group with the TLE group with reference to errors of omission, we obtained a statistical difference $(\mathrm{p}<0.02)$ in the Stroop condition. Additionally, in the control conditions some differences were found such as in the color conditions $(\mathrm{p}<0.005)$ and in the reading conditions $(p<0.001)$; but in the motor controlled conditions $(p=0.2)$ no differences were found.

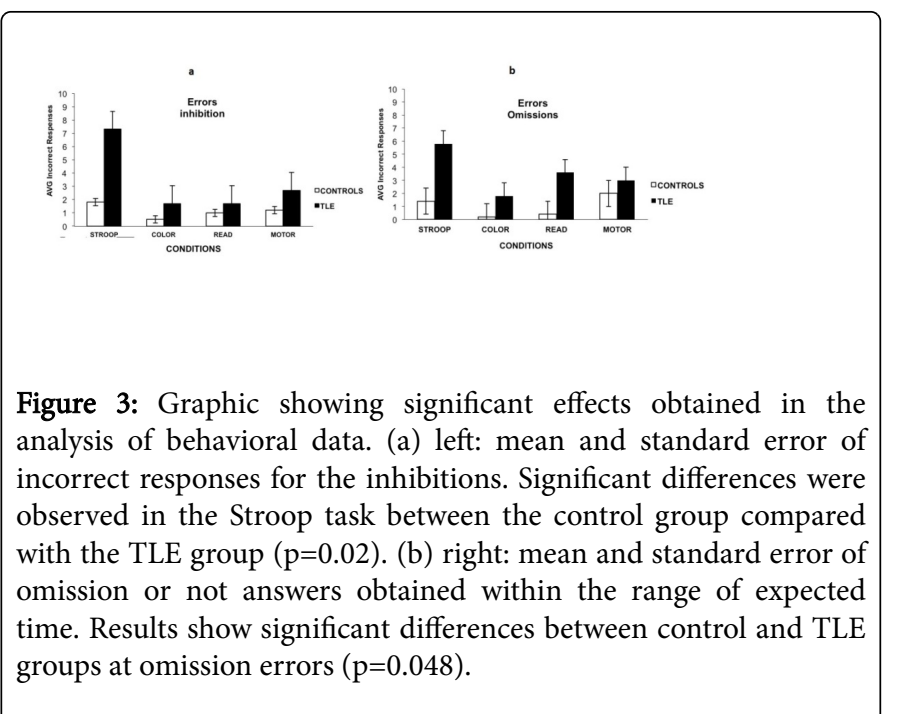

\section{fMRI results}

Stroop conflict processing response of inhibition: The results on the Stroop task were compared to those from the control conditions (motor, read, color) of the TLE group Figure 4. Conflict processing and response of inhibition produced activation in areas of the right FL frontal lobe and the right inferior frontal junction, the right inferior frontal gyrus IFG, the right superior frontal gyrus SFG, the right middle frontal MFG and gyrus, and the right ACC. The TLE patients presented difficulties in the executive system regulated by the frontal lobe; since the beginning they showed a dominant cerebral activation in the right hemisphere and not on the left, as has been observed in normal subjects using the Stroop task with fMRI (Table 2).

\section{Conclusion}

The object of this study was to evaluate the behavioral effects of the processing conflict and response by using the Stroop task in controlled participants and in patients with TLE. Additionally, we wanted to evaluate the brain activation at the processing conflict and the response inhibition function regulated by the frontal cortex, at the orbitofrontal cortex pathways by means of fMRI in the group of patients with TLE.

Using neuroimaging techniques in normal subjects, we identified a dominant activation that conflicts processing in areas of the ACC, and bilaterally Inferior Frontal Gyrus (IFG), anterior insula, the parietal lobe and the prefrontal cortex.

As the areas already mentioned have had major representation in studies already done before with normal individuals, the predominant hemisphere has been the left, except for the area of the ACC and the Inferior Parietal Lobe (IPL) where the right lateral side of conflict processing and response of inhibition is according to the meta-analysis conducted. Our findings were that patients with TLE had a predominantly right activation in the following areas: the Frontal Lobe (FL) and the inferior frontal junction, the inferior frontal gyrus IFG, the superior frontal gyrus SFG, the middle frontal gyrus and the anterior cingulate cortex.

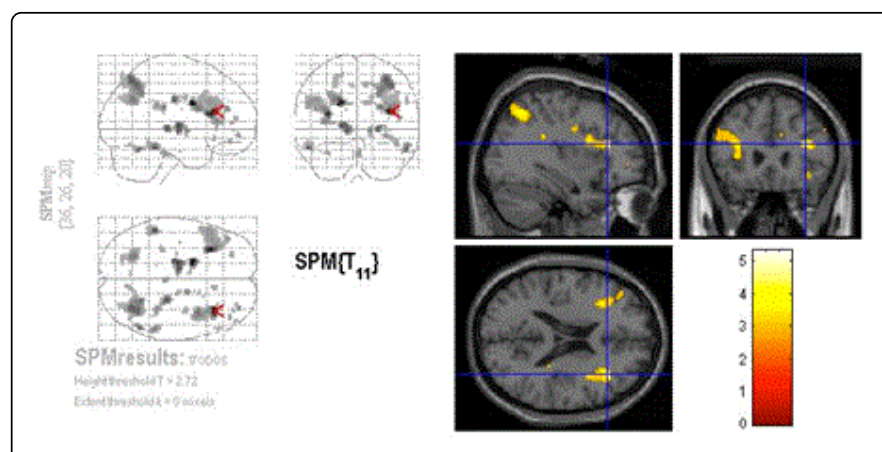

Figure 4: Statistical maps and active regions at the Stroop task from the TLE group. Results from the Stroop task were contrasted with those from the control tasks (motor, reading, color). The scale represents the level of significant activation.

This may suggest a possible brain reorganization for this "executive" process evaluated, since the activation observed in previous studies with normal subjects differ in hemispheric dominance and inferior parietal activation area which was not observed in our selected sample.

\begin{tabular}{|c|c|c|c|c|c|c|c|c|}
\hline \multirow{3}{*}{$\begin{array}{l}\text { Cluste } \\
\mathbf{r} \\
\mathbf{p} \\
\text { (unc) }\end{array}$} & \multirow{3}{*}{$\begin{array}{l}\text { Vovel } \\
\text { FDR }\end{array}$} & \multirow{3}{*}{$\begin{array}{l}\text { Value } \\
\mathbf{Z} \\
\text { voxel }\end{array}$} & \multirow{3}{*}{$\begin{array}{l}\text { Cluste } \\
\mathbf{r} \\
\text { Size }\end{array}$} & \multicolumn{3}{|c|}{ Coordinate } & \multirow{2}{*}{$\begin{array}{l}\text { Anatomical region } \\
\text { (approximate) }\end{array}$} & \multirow{2}{*}{ BA } \\
\hline & & & & \multicolumn{3}{|c|}{$x y z$} & & \\
\hline & & & & 36 & 26 & 20 & R- Frontal Lobe & $\begin{array}{l}\text { 9- } \\
\text { Jun }\end{array}$ \\
\hline & & 2.93 & & 38 & 8 & 22 & $\begin{array}{l}\text { R- Frontal Lobe, } \\
\text { inferior gyrus }\end{array}$ & $\begin{array}{l}\text { 4- } \\
\text { Sep }\end{array}$ \\
\hline & & 2.81 & & 36 & 18 & 20 & $\begin{array}{l}\text { R- Superior Frontal } \\
\text { gyrus }\end{array}$ & 10 \\
\hline & & 2.8 & & 40 & 8 & 26 & $\begin{array}{l}\text { R- Middlle frontal } \\
\text { gyrus }\end{array}$ & - \\
\hline & & 2.73 & & 42 & 4 & 24 & Anterior cingulate & 32 \\
\hline & & 2.43 & & 44 & 16 & 40 & $\begin{array}{l}\text { R- Inferior frontal } \\
\text { juction }\end{array}$ & $\begin{array}{l}\text { 9- } \\
\text { Jun }\end{array}$ \\
\hline
\end{tabular}

Table 2: Regions of BOLD activity BA, Brodmann Area R, Right hemisphere ${ }^{\star} \mathrm{P}<0.001$. Brodmann areas and anatomic areas with its corresponding coordinates of voxels where number BOLD response reached the threshold probability in response during the Stroop test in patients with TLE.

It may be possibly due to the spread of seizure activity affecting extra-temporal regions that regulate the frontal executive system, as well as the likely extra-temporal abnormalities at the gray and white 
matter, which had been associated with the mediation of some functions of the executive system.

According to our behavioral results, we can say that patients with TLE usually make more inhibition and omission mistakes than the control group. We consider that these difficulties are probably related to the increase of the reaction times when responding to the demands at the conflict situation and also related to a difficulty at the inhibitory control, since the patients showed a reaction time higher than the control group.

Attention has a very important function to adequately respond to the demands required for the inhibitory control role. It is functionally related to the Dorsolateral Prefrontal Cortex (DLPFC) as this area plays an important role in attention control and wasn't activated in patients with TLE, as the activation of the bilateral anterior insula was neither observed in patients with TLE, which mainly relates to the process of interference.

Our results give us a better understanding of the neuronal networks involved in the inhibition process regulated by the FC in TLE patients, which indicates a dysfunction related principally to the dorsolateral and medial network of the frontal lobe with medial temporal areas and their mesolimbic cortical-subcortical networks that seem to affect patients with TLE.

These findings also support the hypothesis that the dysfunction in the hippocampus prevents it from fulfilling its role as the comparer of actions, where earlier information (stored in memory) is used to guide future behavior. Normally, current sensorial information would be compared to the information previously stored in memory with respect to the characteristics of the expected stimulus and appropriate responses to it. Thus, the hippocampus cannot perform its normal function and failures appear in the regulation of the frontal lobe that determine an irregularity there, that in the absence of its comparer of action fails to achieve normal activity, as it happened in our sample.

\section{Conclusions}

The TLE patients presented difficulties in the executive system regulated by the frontal lobe. Since the beginning they showed a dominant cerebral activation in the right hemisphere and not on the left, as it has been observed in normal subjects using the Stroop task with fMRI.

These findings emphasize the importance of early diagnosis within fMRI and control treatment, since this will make it possible to provide timely rehabilitation that will enable patients to integrate themselves into a normal life, while preventing later consequences that could reduce their quality of life, since the Executive Functions are crucial for problem-solving, amongst other high-impact functions in people's academic, professional and social development.

\section{Acknowledgements}

Project partially funded by Dirección General de Apoyo al Personal Académico, UNAM, Project \#IN-2284092.

Our sincere thanks to Dr. David Trejo, Dr. Rubén Conde, Dr. Nadia González, Dr. Daniel Santana and Dr. Zeydi Muñoz, for their contributions and support to this study.

\section{References}

1. (1989) Commission on Classification and terminology of the International League against Epilepsy. Proposal for revised classification of epilepsies and epileptic syndrome. Epilepsia 30: 389-399.

2. Jokeit H, Schacher M (2004) Neuropsychological aspects of type of epilepsy and etiological factors in adults. Epilepsy \& Behavior 5: S14-S20.

3. Fisher R, van Emde Boas W, Blume W, Elger C, Genton P, et al. (2005) Epileptic Seizures and Epilepsy: Definitions Proposed by the International League Against Epilepsy (ILAE) and the International Bureau for Epilepsy (IBE). Epilepsia 46: 470-472.

4. Organización Mundial de la Salud (2009) Epilepsy Recuperado el 28 de julio del 2014, de.

5. Vingerhoets G (2006) Cognitive effects of seizures. Seizure 15: 221-226.

6. Elger C, Helmstaedter C, Kurthen M (2004) Chronic epilepsy and cognition. Lancet Neurol 3: 663-672.

7. Campos-Castelló J, Campos-Soler S (2004) Neuropsicología y epilepsia. Rev Neurol 39: 166-177.

8. Amoroso C, Swi A, Somerville E, Groven N (2006) Epilepsy and stigma. Lancet Neurol 8: 1143-1144.

9. Arroyo S (2004) Nuevos fármacos antiepilépticos. En Campos M, Kanner AM, Editores. Epilepsia: diagnóstico y tratamiento. Buenos Aires: Mediterráneo pp: 470-487.

10. Kanner A (2003) The complex epilepsy patient: intricacies of assessment and treatment. Epilepsia 44: S3-S8.

11. Hermann BP (1991) Neurobiological, psychosocial and pharmacological factors underlying interictal psychopathology in epilepsy. Advances in Neurology 55: 437-452.

12. Semester R, Sander J, Koepp M (2007) Long-term retention rates of new antiepileptic drugs in adults with chronic epilepsy and learning disability. Epilepsy Behav 10: 336-339.

13. Volcy M (2004) Epilepsia del lóbulo temporal mesial: fisiopatología, características clínicas, tratamiento y pronóstico. Rev Neurol 38: 663-667.

14. Hermann B, Seidenberg M, Bell B, Ruteck P, Sheth R, et al. (2002) The neurodevelopmental impact of childhood-onset temporal lobe epilepsy on brain structure and function. Epilepsia 43: 1062-1071.

15. Helmstaedter C, Kockelmann E (2006) Cognitive Outcomes in Patients with Chronic Temporal Lobe Epilepsy. Epilepsia 47: 96-98.

16. Funes M, Espinosa M, Sánchez-Álvarez J, Arnedo M, Morales A, et al. (2005) The role of age of seizure onset on executive function in patients with mesial temporal lobe epilepsy [abstract]. Brain Cogn 60:310.

17. Allegri RF, Drake M, Thomson A (1999) Heterogeneidad neuropsicológica en los pacientes con epilepsia del lóbulo temporal mesial. Rev Neurol 29: 11603.

18. Tirapu J, Muñoz J, Pelegrín C, Albéniz A (2005) Propuesta de un protocolo para la evaluación de las funciones ejecutivas. Rev de Neurol 41: 177-186.

19. Stuss D, Alexander M (2000) Executives functions and the frontal lobes: a conceptual view. Psychol Res 63: 289-298.

20. Martín-González R, González-Pérez P, Izquierdo-Hernández $M$, Hernández-Expósito S, Alonso-Rodríguez M, et al. (2008) Evaluación neuropsicológica de la memoria en el trastorno por déficit de atención/ hiperactividad: papel de las funciones ejecutivas. Rev Neurol 47: 225-230.

21. Laurent A, Arzimanoglou A (2006) Cognitive impairments in children with nonidiopathic temporal lobe epilepsy. Epilepsia 47: S99-S102.

22. Cocoran R, Upton D (1993) A role for the hippocampus in card sorting? Cortex 2: 293- 304.

23. Boc `ova JM, Chladek P, Jura J, Hala mek I, Rektor (2007) Executive functions processed in the frontal and lateral temporal cortices: Intracerebral study. Clin Neurophysiol 118: 2625-2636.

24. Xiang-qing Wang, Sen-yang Lang, Hong LU, Lin MA, Yan-ling MAO, et al. (2010) Changes in extratemporal integrity and cognition in temporal lobe epilepsy: A diffusion tensor imaging study. Neurology India 58: 891-899. 
Citation: Alvarez-Alamilla J, Velasco AL, Río-Portilla YD (2016) Conflict Processing and Response Inhibition in Patients with Temporal Lobe Epilepsy: fMRI Study. Epilepsy J 2: 113. doi:10.4172/2472-0895.1000113

Page 6 of 6

25. MacDonald CR, Delis DC, Norman MA, Wetter SR, Tecoma ES, et al (2005) Response inhibition and set shifting in patients with frontal lobe epilepsy or temporal lobe epilepsy. Epilepsy Behav 7: 39-46.

26. Araújo D, Santos AC, Velasco TR, Wichert-Ana L, Terra-Bustamante VC, et al. (2006) Volumetric evidence of bilateral damage in unilateral mesial temporal lobe epilepsy. Epilepsia 47: 438-446.

27. Seindenberg M, Kelly KG, Parrish J, Geary E, Dow C, et al. (2005) Ipsilateral and contralateral MRI volumetric abnormalities in chronic unilateral temporal lobe epilepsy and their clinical correlates. Epilepsia 46: 420-430.

28. Lin JJ, Riley JD, Juranek J, Cramer SC (2008) Vulnerability of the frontaltemporal connections in temporal lobe epilepsy. Epilepsy Res 82: 162-170.

29. Hermann B, Seidenberg M (1995) Executive system dysfunction in temporal lobe epilepsy: effects of nociferous cortex versus hippocampal pathology. J Clin Exp Neuropsychol 17: 809-819.

30. Stretton J, Thompson P (2012) Frontal lobe function in temporal lobe epilepsy. Epilepsy Res 98: 98-113.

31. Drake M, Allegri R, Thomson A (2000) Alteración Cognitiva Ejecutiva de tipo Prefrontal en Pacientes con Epilepsia del Lóbulo Temporal Mesial. Medicina (Buenos Aires) 60: 453-456.

32. Lieb J, Dasheiff R, Engel J (1991) Role of the frontal lobes in the propagation of mesial temporal lobe seizures. Epilepsia 32: 822-837.

33. Martin RC, Sawrie SM, Gilliam FG, Palmer CA, Faugth E, et al. (1996) Wisconsin Card Sorting performance in patients with temporal lobe epilepsy: clinical and neuroanatomical correlates. Cortex 32: 187-190.

34. Kim C, Lee S, Yoo H, Kang J, Lee J (2007) Executive Performance on the Wisconsin Card Sorting Test in Mesial Temporal Lobe. Epilepsy. Eur Neurol 57: 39-46.

35. Horner MD, Flashman LA, Fredes D, Epstein CM, Bakay RAE (1996) Temporal Lobe Epilepsy and Performance on the Wisconsin Card Sorting Test. J Clin Exp Neuropsychol 18: 310-313.

36. Velasco Monroy AL (2013) Epilepsia. Un punto de vista latinoamericano. 1st ed. Edit. Alfil S.A de C.V México, D.F; Capítulo 9: 166-168.
37. Herman B, Wyler A, Richey E (1988) Wisconsin Card Sorting Test performance in patients with complex partial seizures of temporal lobe ring. J Clin Exp Neuropsych 10: 467-476.

38. Strauss E, Hunter M (1993) Wisconsin Card Sorting Performance: effects of age of onset of damage and laterality of dysfunction. J Clin Neuropsych 15: 896-902.

39. Homer M, Flashman L, Freides D, Epstein C, Bakay R (1996) Temporal lobe epilepsy and performance on the Wisconsin Card Sorting Test. J Clin Neuropsych 18: 310-313.

40. Laird A, McMillan J, Peter Kochunov, Turkeltaub P, Pardo J, et al. (2005) A Comparison of Label-Based Review and ALE Meta-Analysis in the Stroop Task. Hum Brain Mapp 25: 6-21.

41. Steel C, Haworth EJ, Hemsley DR, Sharma T, Gray JA, et al. (2001) Neuroimaging correlates of negative priming. Neuroreport 12: 3619-3624.

42. Roberts KL, Hall DA (2008) Examining a supramodal network for conflict processing: A systematic review and novel functional magnetic resonance imaging data for related visual and audiory stroop tasks. J Cogn Neurosci 20: 1063-1078.

43. Brown GG, Kindermann SS, Siegel GJ, Granholm E, Wong EC, et al. (1999) Brain activation and pupil response during covert performance on the Stroop Color Work task. J Int Neuropsychol Soc 5: 308-319.

44. Fan J, Flombaum JI, McCandliss BD, Thomas KM, Posner MI (2003) Cognitive and brain consequences of conflict. Neuroimaging 18: 42-57.

45. Utti B, Graf P (1997) Color Word Stroop test performance across the adult life span. J Clin Exp Neuropsychol 19: 405-420.

46. Golden C (1978) The Stroop color and Word test. A manual for clinical experimental uses. Chicago IL Stoelting.

47. Golden C (1975) The measurement of creativity by the Stroop Color and Word Test. J Pers Assess 38: 502-506.

48. Schneider W, Eschman A, Zuccolotto A (2002) E-Prime User's Guide. Pittsburg: Psychology Software Tools Inc. 